\title{
Prospects of Deliberative Global Governance
}

\author{
Mikko Rask ${ }^{1}$ and Richard K. Worthington ${ }^{2}$ \\ 1. The National Consumer Research Centre, Helsinki 00531, Finland \\ 2. Politics Department, Pomona College, Claremont, California 91711, USA
}

Received: August 26, 2011 / Accepted: November 1, 2011 / Published: April 20, 2012.

\begin{abstract}
Global governance is often equated with international institutions such as the United Nations and the World Bank that were established after World War II to address problems transcending national borders. While these institutions incorporate norms of representative democracy that evolved in national societies, their legitimacy is often questioned on grounds of limited effectiveness and remoteness from the citizens they purportedly serve. The arguments of many democratic theorists that deliberation among ordinary citizens can legitimize policies that heed these views thus bear important implications for global governance. In this paper, the possibility and different ways that civil society enhancing public participation, transparency and accountability in global governance are addressed. The empirical focus will be on the world's first global deliberation-WWViews (world wide views on global warming) that was held in 38 countries with all inhabited continents in 2009. The social drivers that encourage innovation in global democratic governance are analysed, as the main successes and challenges of WWViews and sketch three scenarios of the future of deliberative global governance are based on the experiences and plans around global citizen participation. The authors argue that despite some challenges, such as ensuring high quality of deliberation in highly variant policy cultural contexts and building policy pathways conducive to political impact, the prospects of deliberation in helping solve global environmental and policy problems are high, and likely to see cumulative progress in the near future.
\end{abstract}

Key words: Deliberation, global governance, participatory technology assessment, social movements, future.

\section{Introduction}

Global governance structures are currently in turmoil. Globalization involves factors such as widespread technological systems, unrestricted electronic commerce and finance, and trans-boundary social and environmental problems that make territorially-based governance insufficient and impracticable [1, 2]. According to Scholte [3], national and local governments are unable by themselves to regulate phenomena such as global mass media, ecological problems, arms trade and finance. In response, the regulation of global flows increasingly occurs not through unilateral state action, but through intergovernmental coordination by heterogeneous international organizations, including public, private and civil society actors.

Corresponding author: Richard K. Worthington, professor, Ph.D., main research fields: science and society, environmental policy. E-mail: rworthington@pomona.edu.
Many of the permanent suprastate agencies, such as the UN (United Nations), World Bank, OECD (Organisation for Economic Co-operation and Development), WTO (World Trade Organization), IMF (International Monetary Fund), EU (European Union), and NATO (North Atlantic Treaty Organization) were established after World War II to address problems transcending national borders. While these institutions have retained their key role in steering global relations, their legitimacy is often questioned on grounds of limited effectiveness and remoteness from the citizens they purportedly serve [4].

The regulation of international issues is riven with democratic deficits: decision making by suprastate organizations rests on limited explicit consent from affected populations, and public accountability is generally weak. In understanding the causes of this situation, Scholte [3] identifies two types of structural 
problems. First, practices of democracy have failed to keep pace with the globalization of social relations: most people including politicians continue to view government as the only site for democratic governance, while it seems clear that territorial democratic mechanisms are inadequate to control global actors and flows. Second, the conception of "demos" or the community of people who can exercise collective self-determination is still understood in national terms, while globalization has encouraged individuals to identify in multiple fashions and express transborder solidarities. Combined with the globalized character of problems and institutions that have evolved in recent decades, governance has increasingly become a challenge for "demois", that is, something that can only be effectively undertaken by diverse peoples rather than a single community of people [5]. The persistence of a nationalist mindset in the face of these changes, combined with the fact that state bureaucracies seldom consult their publics about policies on global issues, leads Scholte [3] to conclude that contemporary global spaces are not democratic spaces.

A small but growing number of observers have considered remedies for the paucity of democratic institutions and processes in global governance. Scholte [3] discusses the possibility that civil society can enhance public participation, consultation, transparency and accountability in global governance. In particular, he argues that civil society actors can (1) relay information and analysis to governance agencies and open political space for marginal actors; (2) raise public awareness of international laws and regulatory institutions; (3) fuel debate in and about global governance; (4) increase public transparency; (5) increase democratic control and monitoring of global governance institutions and (6) create spin-offs for the democratization of territorial governance.

In assessing the current and future roles of civil society in democratizing global governance, Scholte [3] remarks that we have witnessed only the early stages of a longer-term project. Until now, the vast majority of global citizens have not participated in civil society activities regarding global governance. A mere expansion of the number of civil society actors would not be sufficient to remedy the democratic deficits, however, since civic associations also tend to underperform with respect to the six potential contributions identified above: (1) civil society tends to give uneven voice to stakeholders and reproduce structural inequalities; (2) focus on behind-the-scenes lobbying and dissemination of flawed knowledge delimits the awareness-raising function; (3) liabilities and co-optation by government agencies can inhibit debates about global governance; (4) the opaqueness of civic organizations' own activities can limit their capacity to increase public transparency of government institutions; (5) self-selected leadership and limited public budgetary oversight undermine their role in democratic control and; (6) following from the previous factors, the democratic territorial spin-off effects can be compromised.

The foregoing critique of the democratic deficit of global governance is the point of departure in this essay, which still focuses on another remedy that has recently been introduced: deliberative global governance. In Section 2, the trend of transnational deliberative governance is examined with particular reference to the world's first global citizen deliberation - world wide views on global warming. Then the different democratic functions of deliberative global governance and social movements are analysed in Section 3. In the final section, factors that are critical in the future shaping of global deliberative practice are identified, in order to draw three different "mini-scenarios" of the prospect of deliberative global governance in the near future.

\section{The Trend of Transnational Deliberative Governance}

DDPs (deliberative democratic processes) have developed significantly since their inception in the late 1960s and institutionalization in the 1980s and 1990s 
[6, 7]. Inspired by the insights of deliberative democratic theorists [8-10], various democratic innovations have been proposed, such as modifications in conventional institutions of government, ways of communicating between government and civil society agencies, uses of e-governance tools, and mass-mediated deliberations [11]. DDPs using "micro-publics" are yet another field of very active democratic innovation. These are forums, where lay citizens and non-partisan actors are gathered together to deliberate topical matters of policy relevance. Examples of such methods include Citizens' Juries, Consensus Conferences, Deliberative Polls, Planning Cells and Scenario Workshops [12, 13].

Until recently, DDPs have been used predominantly at the local and national levels. An emerging trend is the use of DDPs in multiple countries to deal with complex trans-boundary problems. The first such undertaking was Meeting of Minds in 2006, a citizen consultation on brain science that was organized by the EU. Since then, at least five large-scale DDPs have been conducted transnationally [14].

The first DDP at a global level was WWViews (World Wide Views on Global Warming), a citizen consultation on climate policy that was held September 26, 2009 in 38 countries on six continents, and organized by the DBT (Danish Board of Technology). WWViews gave ordinary citizens the opportunity to provide input to their country's delegates to the UN "COP15" climate summit in Copenhagen that was convened in December of the same year. An average of 88 participants per site was seated at tables of 6-8 people, including a facilitator, for purposes of discussing the issues that would be addressed at COP15. A briefing packet was provided to each participant two weeks before the event, and videos summarizing the same information were screened at the deliberations as each of four main topics was taken up, with individual participants indicating their responses to specific policy-oriented questions about the topic at the end of each session. In a final session, participants at each table jointly developed a recommendation to their political leaders [15].

Worldwide, over $90 \%$ of all participants expressed concern about climate change and support for passing a treaty at COP15. Smaller majorities thought that countries violating such a treaty should face severe or significant penalties (83\%), that the average global temperature increase should be held below the 2 degrees centigrade goal that was adopted in COP15 draft treaties (53\%), and that fossil fuel prices should be increased for all but the poorest countries (66\%). Some variations in responses among countries were not surprising. For example, citizens in Russia, the world's top oil producer, were the least likely to be "very" or "somewhat" concerned about climate change (52\%). Other variations might only be explained through more research, such as the comparatively low percentage of Maldivians (60\%) who were "very" concerned about climate change, despite the possibility that the island will have to be evacuated due to rising sea levels [15]. An anomaly like this might reflect a highly effective deliberation that brought some participants to a unique and valuable perspective, one that is at odds with the common sense expectation that most people in a country being overtaken by the seas would be very concerned about climate change. But it could also be the result of organizational flaws in the process. The design of DDPs is a very imperfect science that requires many judgement calls over matters such as briefing information to provide and demographic characteristics to emphasize in recruiting participants. Implementation of the plan is even more uncertain, as it is subject to an array of idiosyncratic developments. For example, who among the people who have committed to participate actually shows up?

Nonetheless, the case analyses produced to date [16], as well as exit surveys from 21 sites and assessments submitted to DBT, all point toward two general outcomes of the world's first global deliberation. First, in both the global north and south citizens were able to meaningfully discuss the policy issues, 
notwithstanding specific situations in which the quality of deliberation might be questioned. Second, nearly all sites disseminated their results to policy-makers and the media, but the climate policy impact in many cases was not measurable, and in the best of cases was minimal.

In sum, WWViews can be judged at this point to be a partial success in the turbulent problem space of global governance. It is unique not only in its democratic ethos, but also in the global qualities that differentiate WWViews from the other trans-border deliberations conducted since 2006. The implicit claim in accounts that describe WWViews as a global event is that its presence on all inhabited continents, indeed its world wide reach, distinguishes it from international processes such as a pan-European deliberation. However, two other factors are more important than geographic reach in distinguishing a global DDP from an international event. First, the pattern of interactions in a global process transcends the familiar channels established by the institutional frameworks of the nation-state era, in which trans-border exchanges are unambiguously inter-national, i.e., between and among nation states and their subjects. Related to this, the participants in a global DDP operate in part as peers in a global space, rather than acting exclusively as citizens in specific nation-states. The signs of this in WWViews were subtle, such as collective greetings exchanged during the deliberations via Skype connections between sites in different countries, or the presence of participants from Egypt, Norway and Vietnam on a panel where WWViews results were presented at COP15. These types of occurrences evince a sense of solidarity that transcends boundaries, more than representing transactions across those boundaries between people with different national identities. International processes are derived from nation-states, while global processes transcend them in important ways. Deliberative global governance, partly because it is deliberative, partakes of such transcendence.
The evolution of DDPs is depicted in Fig. 1. ${ }^{1}$ The trend of transborder deliberations can be measured and described in terms of both quantitative and qualitative metrics. The quantitative indicators are the number and frequency of deliberations, the number of participants, and the number of countries. Qualitative indicators include not only the criteria described above that delineate global and international deliberations, but also measures of democracy. Arnstein's [17] ladder of participation remains a valid model for the latter purpose. It places nonparticipation at the bottom in terms of its democratic significance; "tokenism" in the middle, including citizens' consultations that offer no assurance that their ideas will be taken into account in decision making; power sharing toward the top, including partnerships between citizens and decision makers; and finally, delegation of power to the citizens. WWViews can most accurately be positioned at the middle level in Arnstein's participation ladder, in light of the present knowledge of its political impacts; a longer time perspective is needed, however, to fully understand its wider implications both nationally and internationally [18].

The history of transnational deliberation is based on a handful of examples, and global deliberation only on a single exercise, plus early experience with WWViews on Biodiversity, now scheduled for late 2012. For this reason the next five years will indicate whether this development is a passing fad or a growing practice with prospects for institutionalization. In anticipating the potential for deliberation to become an institutionalized practice in global decision making, it is informative to compare the different roles of deliberation vs. social movements in contributing to

\footnotetext{
${ }^{1}$ Andersson and Shahrokh [14] identify the following international DDPs: meeting of minds (2006); European Citizens Panels (2006-2007); deliberative poll on the future of Europe (2007); European citizens consultation I (2007) and II (2009); and world wide views on global warming (2009), available online at MM: www.meetingmindseurope.eu; ECP: www.citizenspanel.eu; TEDP:http://cdd.stanford.edu/polls/eu/; ECC1\&2: http://www.european-citizens-consultations.eu/; WWV1\&2: www.wwviews.org; all web addresses accessed on April 2, 2012.
} 


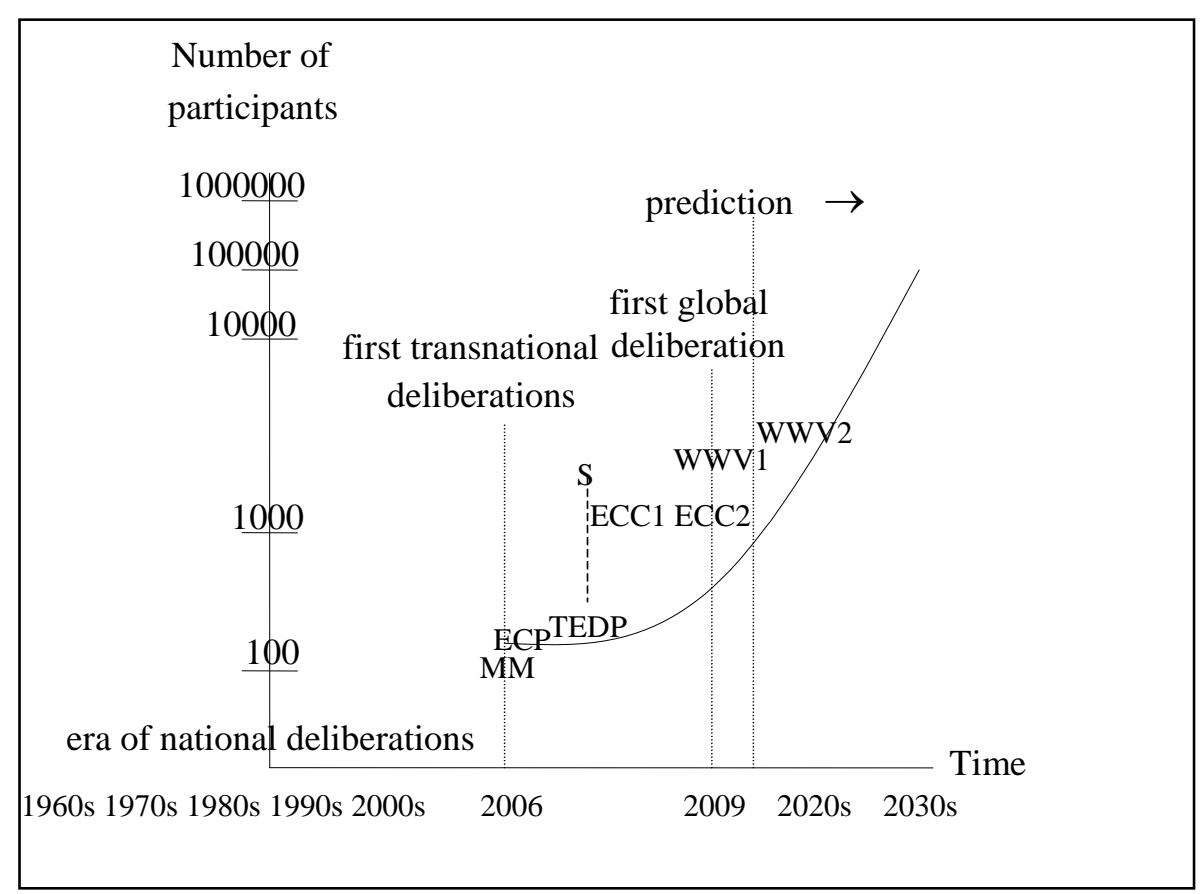

Fig. 1 The trend of transnational deliberative governance. MM = meeting of minds; ECP = European Citizen Panels; TEDP = Tomorrow's Europe: Deliberative Poll ${ }^{\circledR}$, to which a survey (S) was linked; ECC1 \& ECC2 = European citizens consultations I \& II; WWV1 = world wide views on global warming; WWV2 = world wide views on biodiversity (under plan).

international decision processes. Compared to the emerging institutional role of "global deliberation", social movements have reached an established status, and have actively impacted international decision processes such as COP15. ${ }^{2}$

\section{Deliberation vs. Social Movements}

To understand what deliberation is and its potential contributions to social improvement, it is critical to understand what it is not. While the latter category is infinite (because "everything else” is what deliberation is not), the most important distinction to be drawn is between deliberation and social movements. These differences are depicted in seven dimensions in Table 1. Clarifying them is important for three reasons.

First, delineating deliberation and movements stems

\footnotetext{
${ }^{2}$ Non-governmental organizations (NGOs) have a formal role in international bodies such as the United Nations Framework Convention on Climate Change (http://unfccc.int/); they also have a decades-long history in organizing international campaigns, such as the 350.org event on October 24, 2009, a few weeks after the WWViews deliberation, that coordinated 5200 rallies and mass demonstrations in 181 countries to send a message to COP15 (http://www.350.org/en/mission).
}

from Scholte's argument [3] that social movements “underperform" at the global level, suggesting (as research on WWViews has indicated) that deliberation could be understood as a complementary form of social action. However, this complementarity is likely to be counterproductive if the different methods and goals are not appreciated. A clear threat for the deliberative agenda is that cooperation with social movement organizations and campaigns that fail to heed their differences will yield a conflation of the two. This could undermine the credibility of deliberative outcomes as (ideally) the authentic result of interaction among diverse people, whose primary connection to the issue at hand is a concern for the common good.

Second, blurring the differences can generate questionable strategies. Social movements are more familiar than deliberation to policy makers, politicians, activists, and observers, in part because their contentiousness makes them visible. Expectations for what they promise (or threaten) as vehicles of significant social change are therefore likely to be exaggerated, resulting either in naive faith or 
Table 1 Characteristics of social movements and deliberation.

\begin{tabular}{lll}
\hline & Social movements & Deliberation \\
\hline Ontology & Motion & Contemplation \\
Focus & Grievance & Issue \\
Strategy & Contest authorities & Inform authorities \\
Knowledge base & Experience & Science \\
Image & Drama & Talk \\
Participant relations & Solidarity & Citizenship \\
Organization & Spontaneous & Planned \\
\hline
\end{tabular}

unwarranted concern. The authors saw this in their roles as practitioners ${ }^{3}$ in the world's first global deliberation, where they routinely encountered people who projected social movement qualities onto deliberation. For example, one author recently gave a talk to a graduate seminar where a member of the audience interpreted the speaker's concern that too many like-minded "greens" may have been present at WWViews as good news, because it indicated that concerned people were finally unifying to take action. Both points can be valid, but the failure to distinguish them obscures the difference between the interaction among culturally and politically diverse participants in a DDP, which is central to its goals and credibility, and a coalescing of like-minded advocates. A similar conflation could be observed at some of the WWViews sites. For example, one local partner distributed T-shirts emblazoned with a "Save the Earth" slogan that were worn by all participants at the event, and another stated in its participant recruiting materials that providing input to climate policy makers could impact the health of the planet. Sometimes even academic observers have blurred the distinction (e.g., referring to deliberation in the U.S. as a "nascent democracy movement” [19]), although Lee's [20] analysis of deliberation as a "strategic action field" is an important exception. While it may be appropriate for practitioners to partner with social movement organizations in specific tasks (see below), the blurring of deliberation

\footnotetext{
${ }^{3}$ Both authors of this article were national coordinators of the WWViews project: Worthington coordinated the activities in five US states (Arizona, California, Colorado, Georgia and Massachusetts) and Rask in Finland.
}

with social movements can steer a DDP toward pre-conceived outcomes, thereby undermining one of its central purposes.

Third, the participants in social movements (spontaneous or organized through NGOs) can be active, competent and prepared to devote their time and resources to regulatory processes. They also work at the grass-roots level, which makes them strong potential partners in citizen engagement processes, not only in practical terms but also in practicing "soft transfer" of new governance ideas [21]. A prudent partnership between social movements and deliberation could entail new ways of co-operating and turning global spaces to democratic spaces. A global society that learns and institutionalizes the habits of deliberative decision-making will be in a better position to channel larger changes in culture and society in constructive and sustainable directions during the infrequent moments when such opportunities arise. A society that must invent democratic processes amid the maelstrom of change, on the other hand, faces lower prospects for a positive outcome of social movement.

\section{Discussing the Future of Deliberative Global Governance}

The argument to this point is that transnational and global deliberation is a recent phenomenon and trend that is driven by the need to democratize international decision making; the different characteristics of deliberation and social movements through prudent strategies, which can be turned to a mutually beneficial relationship were also highlighted. It is likely that the 
next five years will be critical in understanding whether global deliberation is a passing fad or a growing practice with prospects for institutionalization. While synergies between social movements and deliberation are an important factor in forging the future of global deliberation, other forces will also shape its future. Such forces are next identified in the macro-level of socioeconomic and cultural contexts, the micro-level of methodological evolution, and the meso-level of organizational learning and interaction. Following Wack's [22] classic instruction for scenario planners, these forces are classified into more or less predetermined and uncertain elements, also reflecting their saliency in this development [23, 24].

A severe global recession that took place during WWViews1 was among the most prominent macro-level factors that limited the possibility to secure funding for partners, especially in developing countries. ${ }^{4}$ The economic recovery since 2009, despite its uneven character, provides a more favourable environment than rapid decline, although structural changes toward austerity could turn out to be more important than cyclical recovery. Other macro-level factors impacting the development of deliberative global governance include globalization and its sub-processes, such as the increasingly international character of social and environmental problems (society and environment), the general trend towards multi-level governance structures (politics), globalized markets (economy), pluralism and individualism supporting non-territorial identity building (social values) and growing influence of uncertainties and ambiguities in technoscientific development requiring new consultative tools for decision making (science and technology) [1]. From the perspective of developing deliberative global governance, these macro-level factors are significant, out-of-control and-like the future of the global economy-difficult to predict. In general, however, these factors seem to be

${ }^{4}$ Fifty-five countries joined the project, and 38 ultimately secured the funding needed to conduct deliberations (Bjørn Bedsted, personal communication, May 19, 2011). increasing the demand for innovation in global democracy.

Regarding the micro-level, the method of WWViews was a hybrid based on DBT's and WWViews Alliance members' experience of pTA (participatory Technology Assessment) methods over a period of several decades [25]. The method is based on a gradual evolution of pTA processes reflecting an increasingly rich body of experience and research, which helps in constructing informed and politically robust deliberation processes. The experience from WWViews and other similar deliberation projects indicates that such methods "travel well" to other countries; consensus conferences (another innovation by DBT), for example, have been organized internationally e.g. in Taiwan, South Korea, Japan and Argentina [26, 27]. A gradual and robust methodology development is clear among the strengths of WWViews. The downsides are that there can be a risk of methodological "lock-in", and that the "travel" of the method too often stops at the walls of the deliberation room, resulting in limited or nil political impacts.

The meso-level dynamics of organizational learning and interaction, to our view, constitute the level at which the future of global deliberation based on the WWViews model is most definitely determined. Learning inside the WWViews Alliance was a crucial element of the project, and in light of the fact that many partners had no prior experience with technology assessment or deliberative democracy, it was a true success story that all partners could organize the deliberation events in distant sites according to a common plan. In the long run this network is probably a more important result of WWViews because it has the potential to act as an organized transnational actor who is able to bring "the voice of the ordinary citizens" into global deliberative governance in relation to a broad range of issues.

Another important arena of organizational learning and interaction occurs between the WWViews Alliance 
and national or international policy actors, including NGOs, public authorities and the media. Exchanges in this arena are problematic, however, since increased cooperation with any of these actors would be necessary to ensure the political impact of deliberations, while at the same time there is the risk that deliberation loses its autonomy or is compromised by the different norms of the media and political actors.

In concluding this paper, three future developments that might be expected in deliberative global governance are sketched, any of which might be a defining characteristic in organizing the WWViews2 or similar project, or might be combined in differing degrees.

\subsection{A Contract between Deliberation and NGOs}

Organizing future deliberations co-operatively with NGOs is one model that would entail changes in the current network of actors. Many of the partners in WWViews1 were technology assessment agencies or public research institutes; involving NGOs could enrich the deliberation model by bringing political drama and motion to its current "talk-oriented" image, help effectively include marginalized voices in deliberations (see Table 1), and more practically, provide new skills and expertise needed to handle the changing contents of deliberations.

An alliance with NGOs, at best, could help disseminate the deliberation concept and increase its political relevance (although it should be noted that the role of NGOs in respect to governmental institutions largely depends on the culture of policy making in different countries). For NGOs the cooperation could be an interesting call to bridge the gap between research, governmental and civil society segments that prevail in current societies, and a new tool for more effective articulation and representation of the diverse interests of the civil society. Ultimately, this scenario is about strengthening democratic tools and civil society, and mainstreaming the idea of deliberative global governance. The main challenge in this scenario is to preserve the autonomy and credibility of deliberation and its results.

\subsection{The UN Model}

Closer ties with the UN (or alternatively with other international entities like the World Bank or WTO that are less controlled by the states than UN bodies) would entail changes in the current institutional arrangement of global deliberation. WWViews1 was only loosely integrated to UNFCCC (UN Framework Convention on Climate Change) COP15 summit in Copenhagen (mainly through the Danish Minister for Climate and Energy, Connie Hedegaard, who was an ambassador for WWViews and the hostess of the COP15 summit); closer integration to the UN could significantly increase the global policy relevance of citizen deliberations worldwide.

The UN model is the most likely scenario of WWViews2, since DBT has been negotiating with the UN secretariat for the CBD (Convention for Biological Diversity) that has given its full support to the "World Wide Views on Biodiversity" project and promised to assign staff time from its Secretariat and otherwise promote the project and make it operational [28]. At best, this scenario is about climbing in Arnstein's ladder of participation from "tokenism" toward a partnership between citizens and decision makers, including an assurance that citizens' ideas will be integrated in ongoing discussions and negotiations among policy-makers. The main challenge is to preserve the autonomy of deliberation, and especially, to pay attention that decision makers' interest to safeguard their strategies does not overwhelm the more deliberative function of WWViews.

\subsection{The Media Show Model}

Closer ties with the media would entail new ways of framing and communicating the deliberative process. WWViews1 had a small media footprint, compared to the high expectations of the partners, and compared to other media-focused events such as 350.org's day of 
action on October 24, 2009 (see footnote 2); cooperating with a large international media company, integrating competencies in news media, advertising and public relations in the evolving WWViews Alliance, and profiling the event in a media attractive way could increase its visibility, media impact and political recognition.

The failure to attract an institutional partner with significant access to global media was an important reason for the limited media coverage of WWViews1, and many of the national WWViews partners reported their limited media competences. A revised strategy of better media visibility therefore is an important priority [29]. Seeking political influence primarily through media or overly emphasizing media visibility, on the other hand, seems a misplaced strategy for a deliberation exercise, since it undermines the premise that deliberations should provide fresh ideas outside partisan politics, not just throw fuel to the flames of on-going political debates.

\section{Conclusion}

The prospects of deliberative global governance are exciting. The scholarly ideas of deliberative democracy and local level participatory processes are being shifted to a vehicle of democracy at a global level of politics and public debate. In the long run this process seems unlikely to diminish or cease. However, effective strategies are needed to turn the current successful niche development toward a more significant aspect of global democratic governance.

\section{Acknowledgements}

Mr. Rask's research for this paper is supported by the Academy of Finland Grant number 250234. Mr. Worthington's research for this paper is supported in part by the U.S. National Science Foundation Award number 0925043. Neither funder is responsible for the views expressed in this paper.

\section{References}

[1] S. Joss, Lost in translation? Challenges for participatory governance of science and technology, in: T. Bogner (Ed.), Expertise to What End?, The Ambivalent Connection Between Science and the Public, VS Verlag for Social Science, Wiesbaden, 2005, pp. 197-219.

[2] J. Linnerooth-Bayer, R. Löfstedt, G. Sjöstedt, Transboundary Risk Management, Earthscan, London, 2001.

[3] J. Scholte, Civil society and democracy in global governance, Global Governance 8 (2002) 281-304.

[4] M. Bexel, J. Tallberg, A. Uhlin, Democracy in global governance: The promises and pitfalls of transnational actors in global governance, Global Governance 16 (2010) 81-101.

[5] J. Bohman, Democracy across Borders: From Demos to Demois, MIT Press, Cambridge, 2007. (in Greek)

[6] J. Dryzek, Deliberative Democracy and Beyond: Liberals, Critics, Contestations, Oxford University Press, New York, 2000.

[7] J. Geurts, I. Mayer, Methods for Participatory Policy Analysis: Towards a Conceptual Model for Research and Development, Work and Organization Center (WORC), Tilburg, Netherlands, 1996.

[8] J. Habermas, The Theory of Communicative Action, Reason and the Rationalization of Society, Polity Press, Cambridge, Vol. 1, 1997.

[9] J. Habermas, Theory of Communicative Action, Life World and Systems, Polity Press, Cambridge, Vol. 2, 1998.

[10] J. Rawls, Political Liberalism, Columbia University Press, New York, 1993.

[11] R. Goodin, J. Dryzek, Deliberative impacts: The macro-political uptake of mini-publics, Politics \& Society 23 (2006) 219-244.

[12] O. Renn, T. Webler, P. Wiedemann, Fairness and Competence in Citizen Participation: Evaluating Models for Environmental Discourse, Risk, Governance and Society 10, Kluver Academic Publishers, Dordrecht, 1995.

[13] S. Joss, S. Bellucci, Participatory Technology Assessment: European Perspectives, Centre for Study of Democracy, London, 2002.

[14] E. Andersson, T. Shahrokh, Crossing boundaries with deliberation: But, where are we going?, in: M. Rask, R. Worthington, M. Lammi (Eds.), Citizen Participation in Global Environmental Governance, Earthscan, London and New York, 2011.

[15] B. Bedsted, L. Klüver, World Wide Views on Global Warming From the World's Citizens to the Climate Policy Makers, The Danish Board of Technology, Copenhagen, 2009.

[16] M. Rask, R. Worthington, M. Lammi, Citizen Participation in Global Environmental Governance, 
Earthscan, London and New York, 2011.

[17] S. Arnstein, A ladder of citizen participation, Journal of the American Institute of Planning 35 (1969) 216-224.

[18] P. Sabatier, An advocacy coalition framework of policy change and the role of policy-oriented learning therein, Policy Sciences 21 (1988) 129-168.

[19] A. Fung, J. Goldman, M. Mccoy, B. Wright, Working Together to Strengthen Our Nation's Democracy [Online], White House Office of Science and Technology Policy, 2009, p. 4, http://www.whitehouse.gov/files/ documents/ostp/opengov/sond2\%20final\%20report.pdf.

[20] C. Lee, Five assumptions academics make about deliberation, and why they deserve rethinking, Journal of Public Deliberation 7 (2011) 1-48.

[21] D. Stone, Transfer agents and global networks in the "transnationalization" of policy, Journal of European Public Policy 11 (2004) 545-566.

[22] P. Wack, Scenarios: Shooting the rapids, how medium-term analysis illuminated the power of scenarios for shell management, Harvard Business Review 63 (1985) 139-150.

[23] J. Coates, Scenario planning, Technological Forecasting and Social Change 65 (2000) 115-123.
[24] J. Glenn, Scenarios, in: J. Glenn, T. Gordon (Eds.), Futures Research Methodology 2.0, American Council for the United Nations University, Washington D.C., 2003.

[25] World Wide Views Method [Online], Danish Board of Technology, 2010, http://www.wwviews.org/node/10.

[26] A. Agger, B. Jæger, E. Jelsøe, L. Phillips, The creation of a global voice for citizens-The case of Denmark, in: M. Rask, R. Worthington, M. Lammi (Eds.), Citizen Participation in Global Environmental Governance, Earthscan, London and New York, 2011.

[27] E. Einsiedel, E. Jelsøe, T. Breck, Publics at the technology table: The consensus conference in Denmark, Canada, and Australia, Public Understanding of Science 10 (2001) 83-98.

[28] World Wide Views on Biodiversity, Project Description [Online], The Danish Board of Technology, 2011, http://www.tekno.dk/subpage.php3?article=1739\&survey $=15 \&$ language $=\mathrm{uk}$.

[29] J. Schneider, J. Delborne, Seeking the spotlight: WWViews and the U.S. media context, in: M. Rask, R. Worthington, M. Lammi (Eds.), Citizen Participation in Global Environmental Governance, Earthscan, London and New York, 2011. 